\title{
Research on the Development Path of Chinese Pop Music Industrialization from the Perspective of Culture
}

\author{
Wang Rui \\ Heihe University, Heilongjiang, China
}

Keywords: cultural perspective; popular music; development approach

Abstract: Popular music itself belongs to the category of popular culture, and its development has a certain impact on people's ideas and life habits. Popular music, as the most popular music type in the society at the present stage, reflects the aesthetic tendency of music. However, with the rapid development of the Internet and new media, there are some problems in the development of popular music industrialization. Based on the cultural perspective, this paper briefly explains the development dilemma of popular music at the present stage, analyzes the main characteristics of popular music, and puts forward the development path of the industrialization of popular music in China, so as to improve the connotation and quality of popular music and promote the healthy development of mass culture in China.

\section{Introduction}

China's popular music has experienced more than 30 years since its development in the 1970s. At this stage of development, its influence has gradually penetrated into people's ideas and living habits, and has played an increasingly important role. Especially in recent years, with the rise of the Internet and new media, pop music has become one of the most appealing and influential cultural forms by virtue of its own characteristics of mass culture. This is mainly reflected in the younger generations, the pursuit of pop music can be compared to madness. Although the production and market of popular music has gradually matured, it is in the midst of suffering. The development of popular music has an impact on the development direction of China's popular culture to a certain extent. Therefore, it is especially important to understand the dilemma faced by contemporary pop music in China and to study the development path of China's popular music industry ${ }^{[1]}$.

\section{The predicament faced by popular music in China at the present stage}

\subsection{Pop music development disorder and piracy problems}

At present, the domestic popular music market has many problems. The development and operation of the popular music industry are greatly damaged by the market disorder, the lack of industry norms, the poor operation mechanism and the imperfect legal system. After the reform and opening up, China stepped into the market economy. The blindness and spontaneity of the market economy itself has left a deep imprint on the popular music industry, and the "vigorous" piracy 
industry in the Chinese market has affected the development of the popular music industry everywhere.

\subsection{Pop music lacks excellent creative talents}

The unevenness of the popular music creation group is a major problem in the development of the modern domestic music industry. The network provides convenience for a variety of creators, and there are torrents of popular online songs, but most online creators and singers lack professional training, weak basic skills or no basic skills, and the post-production is rough and rudimentary, resulting in most popular online songs or plain and tasteless. Breakthroughs, distortions in tunes, vulgar lyrics, lack of innovation, plagiarism, etc., have all become stumbling blocks in the development of China's music industry.

\subsection{Popular music lacks theoretical innovation research}

At present, too much administrative intervention leads to the lack of in-depth research on domestic music theory, the lack of theoretical innovation, coupled with the influence of Hong Kong, Macao, Taiwan, Europe, America and other foreign cultures, resulting in the lack of domestic popular music spirit. At the same time, China has a lot of restrictions on cultural publishing, which is extremely unfavorable to the healthy development of music industry ${ }^{[2]}$.

\section{The main features of popular music}

As a typical pop music in the art industry, as its name implies, its strong popularity is a key feature of its innateness. In China, popular music, with this feature, has increasingly developed into a mainstream representative in the art industry. Both the creative concept and the means of performance are linked to the most popular and fashionable elements of the moment, and the means of communication also adopt new technologies such as network and multimedia. At present, the consumer groups of domestic popular music are mostly young people with open minds and rich living, as can be seen from figure 1. Popular music has given its industry commerciality with its fashion, entertainment and artistry, which has produced endless market potential and huge industrial value.

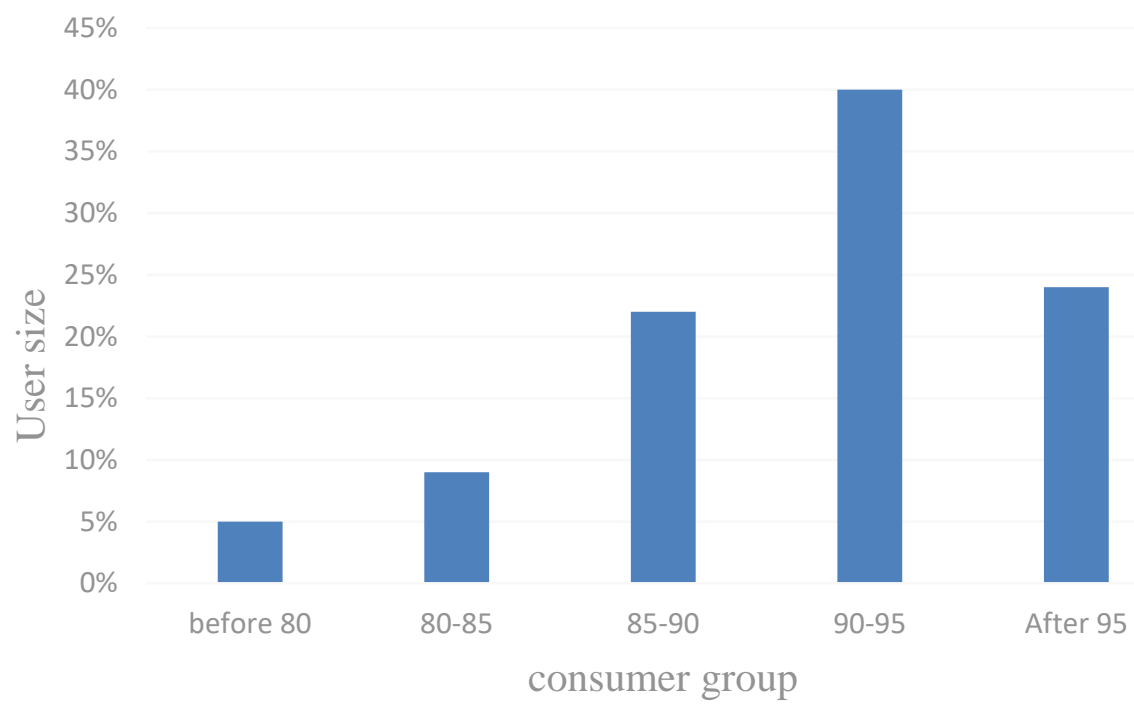

Figure 1 China pop music user behavior report 


\section{An effective way to promote the development of China's pop music industry}

\subsection{Accelerate the cultivation of music talents}

At present, China's music and art management major has not yet formed a complete system in higher education. There are not many colleges offering this subject, which is extremely unfavorable for the development of the popular music industry. The state should increase the input of disciplines and strengthen the research on the basic theories of the popular music industry. Actively explore the general laws and special laws of the popular music industry, cultivate applied talents, and enable China's popular music industry to quickly connect with the international ${ }^{[3]}$.

\subsection{Developing creative culture}

The content of music is the soul of music and the artistic expression of music. As a popular commodity, music should not only pay attention to the commodity attribute of music, but also pay attention to the value attribute of music. Popular music is an important part of creative culture in its own right. Like other cultures, it has both regional and global characteristics. China's popular music industry is still in the development stage, so we cannot abandon China's local culture and blindly imitate Europe, America, Japan and South Korea. Instead, it should be based on China's 5,000 years of traditional culture and absorb the achievements of other countries and regions as the fresh nutrients of the popular music content. Only in this way can China's popular music industry be based on the long term and focus on the future.

\subsection{Make full use of high-tech and other high-tech}

As human society enters the digital age, network modernization has become the mainstream of this era. In order to promote the development and innovation of modern pop music, first of all, we should use modern networks to establish a modern popular music network platform, with free trial and advertising plus advertising fees as the main body, and establish a marketing model of music communication and industrial profit merger. Secondly, the use of the new mobile phone new media, the establishment of unlimited music platform, and cooperation with mobile communications, China Unicom and other communications departments to explore the infinite pop music profit market. Once again, establish a variety of music platforms and establish consumption channels, so that it will come true. Finally, each record company should be consumer-oriented and oriented to the consumer market to create music and art products suitable for this era. It can be seen from figure 2 that the user scale of music in China is on the rise, and the popular music should be constantly created in line with the public's favorite.

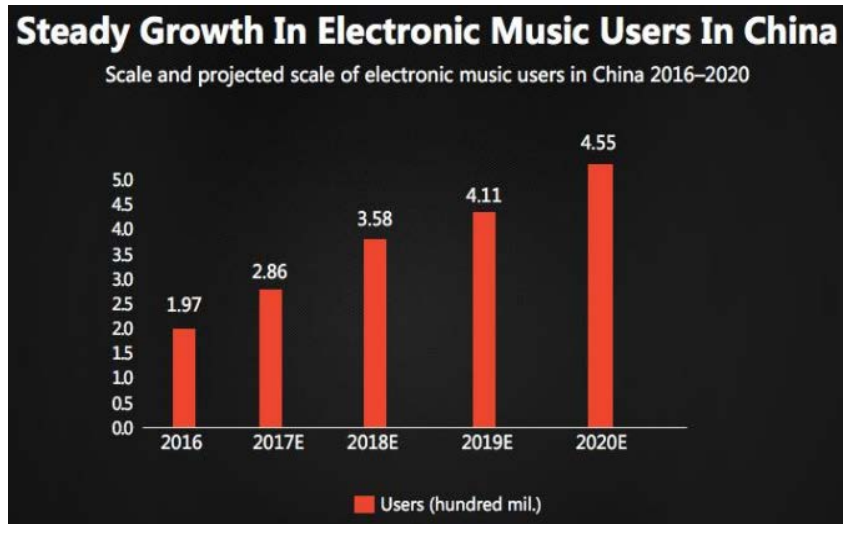

Figure 2 China electronic music user scale 


\subsection{Improve the aesthetic ability of music creators}

The cultural literacy possessed by music creators has a decisive influence on the connotation of their works. Therefore, in order to improve the cultural connotation of popular music, it is necessary to improve the cultural literacy and aesthetic ability of the creators. First, constantly pay attention to the creator's musical perception. Second, constantly improve the literary literacy and noble sentiment of the creators. Third, constantly pay attention to the creator's life and practice accumulation. If the creators of pop music meet the above requirements, their aesthetic ability will rise to a higher level, and the works they create will have more cultural connotations ${ }^{[5]}$.

\subsection{Strengthen copyright protection and regulate popular music market}

The cultural industry also pursues profits. Only by achieving a virtuous circle of industries can the long-term development of the music market be realized. However, various piracy behaviors in the domestic music market have directly led to the damage of the entire music industry's circular chain, and the decline of the music industry's profits, which has caused the cultural industry development funds to be broken, and the music culture has receded. We should use various channels to publicize the concept of genuine ideas to the public, improve the law, resolutely crack down on piracy crimes, and increase the legislation of the music industry to achieve healthy and orderly development of this industry.

At present, the structure of China's music industry is still immature, and the development of the music chain is still not healthy. We should base ourselves on the status quo of China's popular music industry, solve the problems of poor innovation in Chinese pop music, loose management of popular music industry, etc., and join relevant education departments to establish a sound education mechanism and improve the music education mode of colleges and universities. Cultivate professional practitioners, solve all aspects of problems from the source, and enhance the overall quality of domestic popular music creation. On this basis, we will continue to improve the Chinese music industry chain, improve the structure of the music industry, and build a line industry service project such as Chinese popular music copyright, music marketing, music broadband and music wireless business.

\section{Conclusions}

In general, the emergence and development of popular music is of great significance to social culture. China's popular music industry is still in its infancy, which has some disadvantages and deficiencies. In order to better develop popular music, it is necessary to timely adjust some problems and deviations in the development process. Only by accelerating the cultivation of music talents, making efforts to develop creative culture, making full use of new media and other high-tech, improving the aesthetic ability of music creators, strengthening copyright protection, and standardizing the popular music market in China. Only in this way can we constantly meet people's spiritual needs, promote the development of our mass culture and improve our economic growth.

\section{Acknowledgement}

Research on the Operation path of the industrialization of popular Music in Heilongjiang Province No. 18YSE619

\section{References}

[1] Zhou Xiaoyan. Research on Chinese Popular Music in the Perspective of Culture [D]. Suzhou University, 2013. 
[2] Tian Liang. Research on Chinese Popular Music from the Perspective of Culture[J]. House of Drama, 2016(1): 64-64.

[3] Yang Ming. Research on the Path of National Instrumental Music Revitalization under the Vision of Cultural Industry [J]. Market Research, 2013(7): 67-68.

[4] Liu Yutong. A Preliminary Study of Chinese Pop Music from the Perspective of Culture[J]. Sound of the Yellow River, 2017(18): 52-52.

[5] Gao Jing. The "Chinese Style" of Popular Music in the Perspective of Cultural Inheritance[J]. Popular Art, 2013(19): 159-160. 